\title{
0 processo de desenvolvimento de produto imobiliário: estudo exploratório em uma incorporadora
}

\author{
José de Paula Barros Neto UFC \\ João Adriano Ponciano Nobre Construtora Marquise e UFC
}

\section{RESUMO}

Este trabalho tem como objetivo propor melhorias no processo de desenvolvimento de produtos imobiliários em uma empresa de construção civil, utilizando informações provenientes do processo de análise das necessidades dos clientes. A partir de abordagens teóricas e de um estudo empírico, apresenta-se um conceito mais abrangente para o processo de desenvolvimento de produto (PDP) para a construção civil, tendo o método do estudo de caso como estratégia de pesquisa. Analisou-se, inicialmente, o fluxo de informações provenientes dos clientes nos diversos pontos de contato com a empresa. Em seguida, foram criadas as ferramentas para captação das necessidades dos clientes, inserindo-se os seus resultados no PDP da empresa. A formalização da utilização das informações provenientes dos clientes trouxe resultados imediatos para o produto que estava em desenvolvimento durante a pesquisa.

\section{PALAVRAS-CHAVE}

Processo de desenvolvimento de produto, construção civil, processo de projeto, gerenciamento do fluxo de informações, requisitos de clientes.

\section{The development process of immovable product: an incorporator exploratory study}

\begin{abstract}
The aim of this paper is to propose improvements in the product development process (PDP) for construction projects using information from the client needs assessment process. With the use of theoretical approaches and empirical study it was possible to present an ample PDP's concept to a civil construction product. Case study was research strategy used in this paper. Initially, the authors used the Data Flow Diagram tool to analyze the information flows that arise from each point of contact between the clients and the company. After that, a tool to capture customers' needs was developed and its results served as a basis for the company's new product development process. The formal information provided by the tool was used to develop a product at the same time this research was being carried out.
\end{abstract}

\section{KEY WORDS}

Product development process, civil construction, design process, information flow management, customer requirements. 


\section{INTRODUÇÃO}

O sucesso de um produto decorre, em grande parte, da elaboração de um competitivo processo de concepção, pois sabe-se que os custos com erros são bem menores se detectados na fase inicial de desenvolvimento se comparados com aqueles verificados por ocasião do lançamento do produto. Huthwaite (apud GIROTO, 1998) estima que os custos de um processo de concepção aumentam em múltiplos de dez à medida que o projeto progride em suas etapas.

\section{CARACTERÍSTICAS DO PDP NA INDÚSTRIA DA CONSTRUÇÃO CIVIL}

Segundo Silva (apud PORTO, 1999), a indústria da construção civil, a partir dos estudos atuais da economia industrial, passou a ser analisada não mais como uma atividadefim isolada, mas, sim, através de uma visão mais ampla, na qual se analisam ligações entre a indústria da construção civil - subsetor edificações (ICCSE) - e as várias cadeias produtivas, a montante e a jusante, que fornecem os insumos necessários para a realização de um projeto concebido.

Verifica-se, também, que na ICCSE, o valor do produto é obtido a partir dos projetos que buscam atingir as condições ótimas para o cliente, apoiando-se nos fundamentos da qualidade total, análise de valor, just in time, entre outros. Nesse sentido, o projeto fornece especificações e detalhes do produto e a produção encarrega-se de executá-las conforme

Na construção civil, a crescente competitividade do setor e o aumento das exigências dos clientes finais têm pressionado empresas a oferecer produtos de melhor qualidade, executados dentro de prazos definidos e com custos cada vez menores (MIRON, 2002). Portanto, a melhoria do processo de desenvolvimento de produtos torna-se uma necessidade para as empresas que querem se tornar competitivas no mercado.

Verificou-se, na literatura especializada, que existem lacunas de conhecimento quanto ao desenvolvimento deste assunto, pois a maioria dos trabalhos foca somente o processo de projeto (MIRON, 2002; TZORTZOPOULOS, 1999), deixando as demais atividades do desenvolvimento de produto (planejamento de comunicação, planejamento de vendas, criação das peças de comunicação, etc.) em segundo plano. Além disso, as pesquisas que trabalham gerenciamento de informações na construção civil (BERNARDES, 1996; CINTRA; AMORIM, 1998; ZEGARRA, 2000) não enfocam diretamente a inserção de informações no PDP.

Sendo assim, o objetivo deste artigo é propor melhorias no processo de desenvolvimento de produtos (PDP) imobiliários em uma incorporadora, utilizando informações provenientes das necessidades dos clientes.

Após esta breve introdução, passa-se à análise de aspectos relacionados à construção civil, ao gerenciamento das informações dos clientes e ao processo de desenvolvimento de produto, como embasamento teórico para o desenvolvimento do estudo. Na sequência, apresenta-se, de forma detalhada, a metodologia utilizada, os resultados analisados logo em seguida, e, posteriormente, são apresentadas as considerações finais da pesquisa. determinado, gerando o risco de haver diminuição no valor do produto, caso a sua execução não esteja de acordo com o especificado (BARROS NETO, 1999).

O processo de desenvolvimento do produto na Construção Civil, por sua vez, difere das demais indústrias devido às peculiaridades do seu produto, que, segundo Oliveira (1997), são as seguintes:

- A complexidade do mercado imobiliário, que envolve inúmeros atributos capazes de influenciar a tomada de decisão;

- O produto possui um longo ciclo de aquisição-usoreaquisição, geralmente devido ao comprometimento de uma considerável parcela do orçamento familiar durante um longo período de tempo;

- A longa duração da vida útil do produto, que implica em um período extenso de uso e manutenção, durante o qual o produto deve atender às necessidades dos usuários; $\mathrm{e}$

- O impacto ambiental gerado por sua intervenção no espaço urbano e pelas próprias relações do ambiente com o comportamento humano.

Além disso, deve-se destacar que o produto da construção civil é único e não seriado, com localização permanente, o que dificulta a constância de processos e todos os demais aspectos que envolvem a sua produção (MIRON, 2002). Existe, também, um visível distanciamento entre projetistas e construtores, o que favorece a perda de informações.

Deve-se entender o produto na construção civil como o empreendimento todo (OLIVEIRA, 1997). Desse modo, a unidade habitacional (o apartamento) é parte do produto, 
bem como a área de lazer, as áreas comuns e toda a infraestrutura que o empreendimento proporciona ao morador.

Verifica-se, ainda, que entre projetistas e usuários do produto existem dois intermediários: construtores e corretores de imóveis, que filtram e enviesam as informações, dificultando o desenvolvimento de produtos adequados aos clientes (FABRÍCIO, 2002).

\section{A IMPORTÂNCIA DO RELACIONAMENTO COM OS CLIENTES E A GERAÇÃO DE VALOR}

As informações obtidas através de um bom relacionamento com o cliente têm extrema importância na alimentação do processo de desenvolvimento de produto. É a partir dessas informações que se pode alterar componentes ou reprojetar o produto adquirido pelos clientes. Busca-se, então, gerar valor a partir do que é considerado por Austin (apud KELLY, 2007) como sendo a relação entre o custobenefício para se obter um produto em relação aos recursos disponibilizados.

No caso da construção civil, em particular com relação à compra de um imóvel, é importante que a incorporadora acompanhe esse relacionamento através de pesquisas de mercado, avaliações pós-ocupação ou medições periódicas da satisfação do cliente. Além disso, quando o imóvel é vendido em planta, a construtora pode ampliar esse contato e já obter informações durante a etapa de construção do imóvel.

A finalidade desse acompanhamento é encontrar os itens que geram valor para o empreendimento, pois, de acordo com Leinonen e Huovila (apud MIRON, 2002), o processo de geração de valor na Indústria da Construção Civil envolve três fases: encontrar os requisitos do cliente; criar soluções para atender estes requisitos; e garantir que estes requisitos sejam atendidos da melhor maneira possível durante o projeto e, posteriormente, na produção.

Sendo assim, o projeto tem uma importante posição na agregação de valor ao produto final, pois é nesta fase que existe a preocupação com a compreensão das necessidades do cliente e com a transformação destas necessidades em um produto.

Portanto, para uma empresa ter sucesso em um empreendimento, é necessário que conheça as necessidades do seu cliente, coletando os dados certos sobre seus requisitos e sabendo retroalimentá-los no processo de desenvolvimento de um novo produto.

Tradicionalmente, a realização desse tipo de trabalho concentra-se na modelagem de empresas e de seus processos de negócios a partir de diferentes tipos de métodos, consis- tindo num conjunto coerente e complementar de modelos a partir de vários aspectos de uma organização, tendo por objetivo auxiliar um ou mais usuários de uma empresa em algum propósito (VERNADAT apud AMARAL, 2002).

Existem, na literatura, diversas ferramentas que apoiam o levantamento e a modelagem de processos. Uma tendência nesse aspecto são os gerenciadores de Workflow, utilizados na automação de processos empresariais internos, e os sistemas de Business Process Modeling (BPM), que propõe integração das informações, colaboração entre as pessoas e automação dos processos (FISHER, 2004). Entretanto, de acordo com o Delphi Group (2003), ainda existe certa resistência a sistemas BPM, em virtude da ausência de um business case claramente definido. Além disso, existem os modelos ISO e SADT/IDEF, que são voltados para a área industrial, de automação, integração e programação máquina-ferramenta (AMARAL, 2002)

Outro método bem conhecido e amplamente utilizado é o ARIS - Architecture of Integrated Information Systems, empregado no desenvolvimento da arquitetura e que conta com uma ferramenta computacional, denominada ARIS Toolset, desenvolvida pela empresa IDS-SCHEER, para auxiliar na sua manipulação (AMARAL, 2002). Uma descrição mais detalhada da arquitetura ARIS pode ser verificada em Scheer (1998), Benedictis et al. (2004) e Amaral (2002).

Zhu e Augenbroe (2006) apresentam, por sua vez, um modelo conceitual de suporte à integração de informações interorganizacionais em projetos ligados à construção. Este modelo divide-se em quatro partes: (1) informações sobre tarefa; (2) contexto; (3) organização; e (4) negócio. O intuito é apresentar uma framework sobre a captura dos principais conceitos e requisitos de um processo colaborativo em um ambiente de projeto virtual, de tal forma a dar suporte ao desenvolvimento de um sofisticado API (Application Programming Interfaces) para melhorar a colaboração entre softwares organizacionais.

Pati e Augenbroe (2007) apresentam outro modelo que agrega informações sobre a experiência do usuário relacionada a projetos de edificações. Tal modelo identifica informações sobre os locais de uso (prédio, piso, espaço etc.), o as-built das partes de cada local (parede, piso etc.), os dados funcionais dos espaços (altura, largura etc.) e a avaliação pós-ocupação de cada espaço. Os autores concentram-se em desenvolver um modelo para analisar dados de uso e ocupação de espaços de forma a subsidiar projetos futuros.

Entretanto, é necessário deixar claro que as vantagens do uso de ferramentas de auxílio são diversas, variando de acordo com as possibilidades da própria ferramenta, assim como os objetivos determinantes do trabalho. Neste caso, adotouse o Diagrama de Fluxo de Dados (DFD) pela facilidade de 
uso e pelo fato de ser uma das ferramentas mais debatidas e utilizadas para a análise do fluxo de informações na construção civil (KENDALL; KENDALL apud BERNARDES, 1996; TZORTZOPOULOS, 1999).

O DFD, segundo Yourdon (1990, p. 177), é uma "ferramenta de modelagem que nos permite imaginar um sistema como uma rede de processos funcionais, interligados por 'dutos' e 'tanques de armazenamento' de dados'. Nesse sentido, pode-se trabalhar o DFD como um facilitador da comunicação com o usuário, apoiando o desenvolvimento de novos sistemas, mostrando a sequência de transformação dos dados pelas diversas áreas envolvidas no processo, sem, entretanto, considerar as particularidades das transformações sofridas (DAVIS apud CINTRA; AMORIM, 1998).

Em relação aos componentes do DFD, Yourdon (1990) descreve a seguinte sequência: (a) processo: é o primeiro componente de um DFD e mostra como uma ou mais entradas são convertidas em saídas - representado por um círculo; (b) fluxo: utilizado para demonstrar o movimento de pacotes de informações de um ponto a outro do sistema - represen- tado por uma seta; (c) depósito: permite que se modele uma coleção de dados em repouso - representado por duas linhas paralelas ou por um retângulo aberto em um lado; e (d) terminador: faz o papel das entidades externas com as quais o sistema se comunica - representado por um retângulo.

Porém, para o desenvolvimento deste trabalho, levou-se em consideração uma representação mais recente do DFD, apresentada por Cintra e Amorim (1998), conforme a Figura 1.

\section{O PROCESSO DE DESENVOLVIMENTO DE PRODUTO}

Smith e Morrow (apud MIRON, 2002) apresentam o desenvolvimento do produto como um processo que converte necessidades e requisitos dos clientes em informação para que um produto ou sistema técnico possa ser produzido. A expressão desenvolvimento do produto, contudo, tem sido utilizada por diversos autores com significado e abrangência distintos.

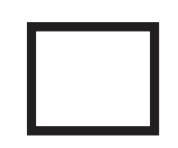

Representa uma entidade externa (uma empresa, uma pessoa ou um departamento), definindo a origem ou o destino do dado

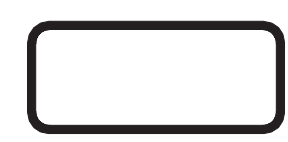

Representa um processo de transformação de dados. Ou seja, a transformação de um fluxo de dados de entrada em um fluxo de dados de saída

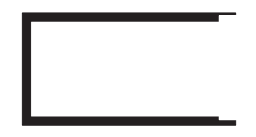

Representa um depósito de dados, ficando permitido o acesso aos dados arquivados

Representa o fluxo de dados de um ponto a outro do sistema. Através de duas flechas paralelas em sentidos opostos, pode-se representar 0 fluxo de informações que ocorre de maneira simultânea

Figura 1: Representação de um DFD 
No Quadro 1, são apresentadas as principais etapas do desenvolvimento do produto propostas em quatro publicações: Clark e Wheelwright, 1993; Yazdani e Holmes, 1999; Ulrich e Eppinger, 2000; Bruce e Cooper, 2000 (MIRON, 2002). O objetivo é realizar um comparativo da evolução desse conceito e da visão de cada autor.

Para Clark e Wheelwright (apud MIRON, 2002), o PDP se divide em desenvolvimento do conceito, planejamento do produto, engenharia do processo e do produto e produção-piloto. Já Yazdani e Holmes (apud MIRON, 2002), subdividem a primeira etapa do PDP dos primeiros autores em marketing e projeto do conceito. Além disso, estes autores tratam da criação de protótipos, etapa que os primeiros autores não mencionaram em destaque.

A proposta de Ulrich e Eppinger (apud MIRON, 2002) é semelhante à de Clark e Wheelwright (apud MIRON, 2002). Entretanto, dá mais destaque ao detalhamento do projeto e ao refinamento e teste do produto.

Já Bruce e Cooper (apud MIRON, 2002) tratam de um lado um pouco mais comercial, quando dão destaque às etapas de lançamento e retirada do produto. Além disso, dividem o desenvolvimento do conceito em geração da ideia e teste desse conceito. Vale salientar também o destaque dado à etapa de estudo de viabilidade, provando a preocupação desses autores com a questão financeira do novo produto.

Apesar dessa variedade, os autores concordam com a ideia de que desenvolver um produto que atenda às necessidades de qualidade dos clientes, em tempo hábil e a um custo compatível com seus concorrentes, é função do processo de desenvolvimento de produto.
Contudo, o PDP pode ter duas concepções: a tradicional e a moderna. A concepção tradicional, tem como fundamento a especialização funcional, legado da abordagem mecanicista de Taylor, Fayol e Ford, que utiliza a especialização como meio de obter eficiência nos processos organizacionais (SILVA, 2001). Só é satisfatória em ambientes estáveis, onde se encontra baixo grau de incerteza, pois é de fácil controle

\section{aumento das exigências dos clientes finais tem pressionado as empresas a oferecer produtos de melhor qualidade}

e previsível. Sua principal desvantagem ocorre quando, em projetos complexos, existe um elevado consumo de recursos. Já o enfoque moderno de desenvolvimento de produtos, está muito mais preocupado com a qualidade do projeto, prevendo a aplicação de ferramentas para assegurar a qualidade e a agilidade no desenvolvimento das atividades de projeto (COELHO, 1998).

\section{A EXTRAPOLAÇÃO DO PROCESSO DE PROJETO PARA A CRIAÇÃO DO PDP NA CONSTRUÇÃO CIVIL}

Na construção civil, o processo de projeto está ocupando o papel representado pelo Processo de Desenvolvimento de Produto na indústria em geral, pois é o processo responsável pela transformação do conceito do empreendimento em

Quadro 1: Principais etapas do desenvolvimento do produto.

\begin{tabular}{|c|c|c|c|c|c|c|c|c|}
\hline \multicolumn{8}{|c|}{ PRINCIPAIS ETAPAS DO DESENVOLVIMENTO DO PRODUTO } & \\
\hline $\begin{array}{c}\text { Clark e } \\
\text { Wheelwright } \\
\text { (1993) }\end{array}$ & \multicolumn{2}{|c|}{$\begin{array}{l}\text { Desenvolvimento do } \\
\text { Conceito }\end{array}$} & \multicolumn{2}{|c|}{ Planejamento do Produto } & \multicolumn{2}{|c|}{$\begin{array}{c}\text { Engenharia do Processo e do } \\
\text { Produto }\end{array}$} & \multicolumn{2}{|c|}{ Produção Piloto } \\
\hline $\begin{array}{c}\text { Yazdani e } \\
\text { Holmes (1999) }\end{array}$ & Marketing & $\begin{array}{c}\text { Projeto do } \\
\text { Conceito }\end{array}$ & $\begin{array}{l}\text { Projeto do } \\
\text { Detalhe }\end{array}$ & \multicolumn{2}{|c|}{ Prototipagem } & $\begin{array}{c}\text { Projeto do } \\
\text { Processo }\end{array}$ & \multicolumn{2}{|c|}{$\begin{array}{c}\text { Preparação para o Processo } \\
\text { de Produção }\end{array}$} \\
\hline $\begin{array}{c}\text { Ulrich e } \\
\text { Eppinger (2000) }\end{array}$ & \multicolumn{2}{|c|}{ Planejamento } & \multicolumn{2}{|c|}{ Desenvolvimento do Conceito } & Projeto & $\begin{array}{l}\text { Projeto do } \\
\text { Detalhe }\end{array}$ & $\begin{array}{l}\text { Refinamento e } \\
\text { teste }\end{array}$ & $\begin{array}{l}\text { Produção } \\
\text { Piloto }\end{array}$ \\
\hline $\begin{array}{c}\text { Bruce e Cooper } \\
\text { (2000) }\end{array}$ & $\begin{array}{l}\text { Geração da } \\
\text { ideia }\end{array}$ & $\begin{array}{l}\text { Teste do } \\
\text { conceito }\end{array}$ & $\begin{array}{l}\text { Estudo de } \\
\text { viabilidade }\end{array}$ & $\begin{array}{c}\text { Desenvolvi- } \\
\text { mento e } \\
\text { Projeto }\end{array}$ & $\begin{array}{c}\text { Testes e } \\
\text { Tentativas de } \\
\text { Campo }\end{array}$ & $\begin{array}{c}\text { Lançamento } \\
\text { do Produto }\end{array}$ & $\begin{array}{l}\text { Revisão do } \\
\text { Desempenho }\end{array}$ & $\begin{array}{c}\text { Retirada do } \\
\text { Produto }\end{array}$ \\
\hline
\end{tabular}

Fonte: Miron, 2002 
projeto e daí em um produto. Na realidade, dentro de uma visão mais ampla, este processo de projeto deve fazer parte do PDP, pois possui diversas limitações quando se faz essa comparação entre a indústria seriada e a da construção civil.

Na indústria seriada, para o desenvolvimento de um novo produto, são necessárias várias etapas não consideradas, de forma geral, na construção civil: pesquisas de mercado, identificação de oportunidades de negócios, formulação das estratégias de marketing, execução de projetos que caracterizam e especificam o produto, caracterização da produção (desenvolvimento do processo), fabricação de protótipos e simulação do desempenho do produto e do processo (FABRÍCIO, 2002), estando, dessa forma, o PDP da construção civil mais ligado ao projeto do edifício do que ao desenvolvimento do produto empreendimento. ações e utilizando uma lógica comparativa entre teoria e prática (YIN, 2001).

Pode-se afirmar, também, que esta pesquisa possui uma visão exploratória, visto que busca conhecer o processo de desenvolvimento de produto da construção civil, explorando as lacunas de conhecimento sobre este assunto.

Este trabalho utilizou o estudo de caso com intervenção (BARROS NETO, 1999) como estratégia de pesquisa para atingir o objetivo proposto. Com esta estratégia de pesquisa, objetiva-se capturar informações valiosas na busca de explorar o problema em questão, seguida da avaliação e solução de problemas (COOPER; SCHINDLER, 2003).

O estudo foi realizado em uma única empresa devido à necessidade de aprofundamento na discussão e análise do tema. O desenvolvimento de produto é um processo longo e complexo, que se inicia desde a concepção de um novo produto e vai até o acompanhamento de uso do empreendimento (Figura 2b). Este aprofundamento no estudo gera um melhor entendimento de todas as etapas do processo dentro da mesma empresa.

Devido à empresa possuir empreendimentos nas diversas fases de desenvolvimento (concep-

Neste trabalho, pretende-se, então, ampliar o conceito do processo de projeto, situando-o dentro do PDP, que também possui etapas de comercialização, planejamento de comunicação, entre outras, de tal forma que se possa caracterizar esse processo não mais como voltado para o projeto e sim para o produto. Sendo assim, começa-se a trabalhar com o conceito de desenvolvimento de produto para a construção civil.

Com base nessas etapas consideradas no desenvolvimento de produtos na indústria seriada, faz-se uma nova visão do processo de projeto. O objetivo é adaptar, para a construção civil, todas estas etapas há pouco citadas, inserindo-as no processo de projeto, ampliando-o para uma nova dimensão, que é a de desenvolvimento de produto (NOBRE, 2005).

Utilizou-se, neste trabalho, a divisão proposta por Miron (2002), por se caracterizar como mais próxima ao conceito apresentado de desenvolvimento de produto. Daí, extrapolou-se para a inserção das atividades que transformam esse processo no processo de desenvolvimento de produto, como pode ser visualizado na Figura 2.

\section{MÉTODO DE PESQUISA}

Trata-se de uma pesquisa de caráter qualitativo, com intuito de compreender os fatos através de uma visão não numérica e não estatística, descrevendo o significado das ção, anteprojeto, projeto legal, projeto executivo, etc.), pôdese estudar todo o processo de desenvolvimento de produto em um prazo viável, entendendo como o processo acontece do início ao fim na mesma empresa.

Este estudo baseou suas evidências em cinco fontes distintas de informações: documentos da empresa, registros em arquivo, entrevistas, observação direta e observação participante. Com a utilização dessas fontes de evidências, foi possível realizar um processo de triangulação de dados, conforme preconiza Yin (2001). O objetivo era fazer avaliações do mesmo fenômeno com a finalidade de obter sua validação, reduzindo ao máximo o risco de enviesamento da pesquisa.

\subsection{Delineamento da pesquisa}

Para a realização desta pesquisa foi demandado um período de oito meses de visitas e entrevistas, nos quais se buscou permanecer diariamente na empresa durante todo o horário de expediente, com o objetivo de melhor compreender o fluxo de informações dentro dos setores.

A pesquisa iniciou-se com uma revisão bibliográfica, em seguida procedeu-se à elaboração dos instrumentos de coleta de dados. Foram montados os roteiros para se conduzir as entrevistas semiestruturadas, sendo um para o setor de Marketing, um para o setor de Pré-incorporação e outro para os demais setores da empresa que mantinham contato com o cliente (Comercial, Obra, Contas a Receber e Atendimento a Cliente). 
Após esta fase inicial, dividiu-se a pesquisa em seis etapas com a finalidade de conseguir o encadeamento das evidências (Figura 3). Cada etapa gerou resultados que serviram de informação para a etapa seguinte, de modo que a etapa seguinte somente ocorria após a conclusão da etapa anterior, possuindo seus dados analisados e discutidos com a empresa pesquisada, excetuando-se as etapas 3 e 4 , que foram realizadas em paralelo.
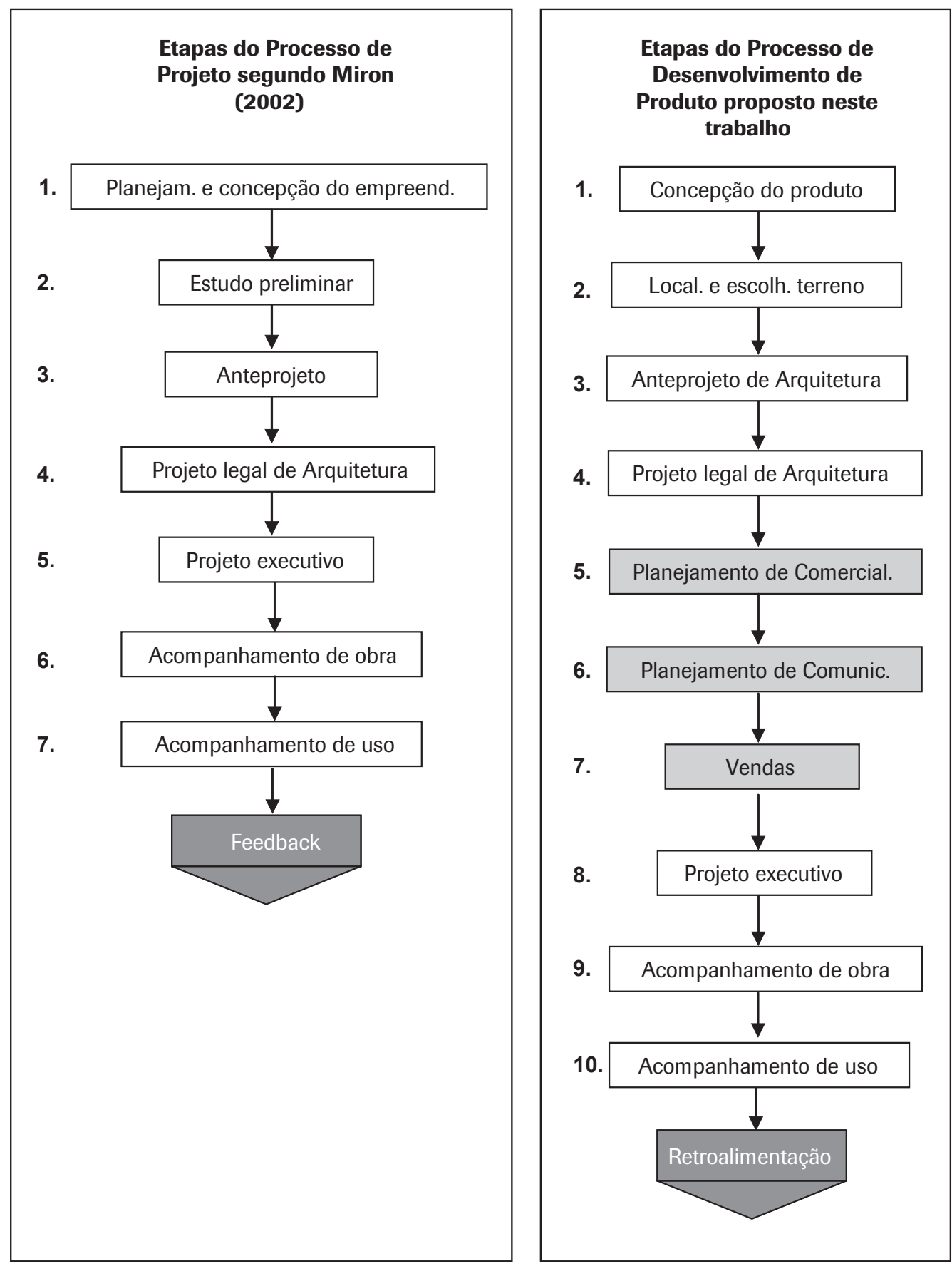

Figura 2: Comparativo entre o Processo de Projeto de Miron (2002) e o Processo de Desenvolvimento de Produto proposto neste trabalho. 
Inicialmente, realizou-se um diagnóstico da empresa com o intuito de entender sua estrutura, conhecer os setores que mantinham contato com os clientes, ou que necessitavam de informações sobre os clientes, etc. Para isso, o organograma da empresa foi analisado e, a partir dele, definiram-se os setores a serem estudados.

\section{$\Delta$ melhoria do PDP é a inserção da voz Ado cliente neste processo}

Através de entrevistas com os responsáveis destes setores (Comercial, Obras, Atendimento a Clientes, Marketing e Contas a Receber), procurou-se entender como a informação do cliente chegava a cada setor (formas de contato); como a informação era capturada (ferramentas de controle de informação utilizadas); para quem e como era repassada (formalização do envio da informação), além de constatar como era arquivada (banco de dados). Sendo também verificada a interação do setor entrevistado com os participantes do desenvolvimento de novos produtos (setor de pré-incorporação, projetistas, agência de publicidade, etc.). Estas entrevistas tiveram uma duração média de 50 minutos.

Após a análise de cada entrevista, fez-se uma montagem inicial do caminhamento da informação do cliente em cada setor. Dessa forma, conseguiram-se identificar as limitações de cada setor com relação ao nível de informação que possuía, bem como verificar os erros e falhas de comunicação entre os setores e a inexistência de processos para a coleta das informações dos clientes.

A elaboração dos fluxos foi baseada no uso do DFD, no qual se identificou a informação, seu caminhamento percorrido (origem e destino) e os responsáveis por cada trecho do fluxo.

Através da entrevista realizada com o setor de pré-incorporação, obteve-se uma primeira visão do processo de desenvolvimento de produtos na empresa. As demais entrevistas com os outros setores contribuíram para aprimorar a visão das atividades e responsabilidades do setor de pré-incorporação.

Além do fluxograma das etapas do processo, montou-se também a planilha de insumo-processo-produto (IPP), que teve a função de identificar em cada etapa do processo que informações eram necessárias para a realização da etapa e que produtos deveriam ser gerados após a realização dessa etapa (TZORTZOPOULOS, 1999).

Em paralelo, foram criados instrumentos de coleta de informações nos setores que possuem contato direto com o cliente, sendo que cada setor colhia informações específicas do cliente.

O objetivo era obter informações dos intervenientes do processo de desenvolvimento de produto, de modo que as

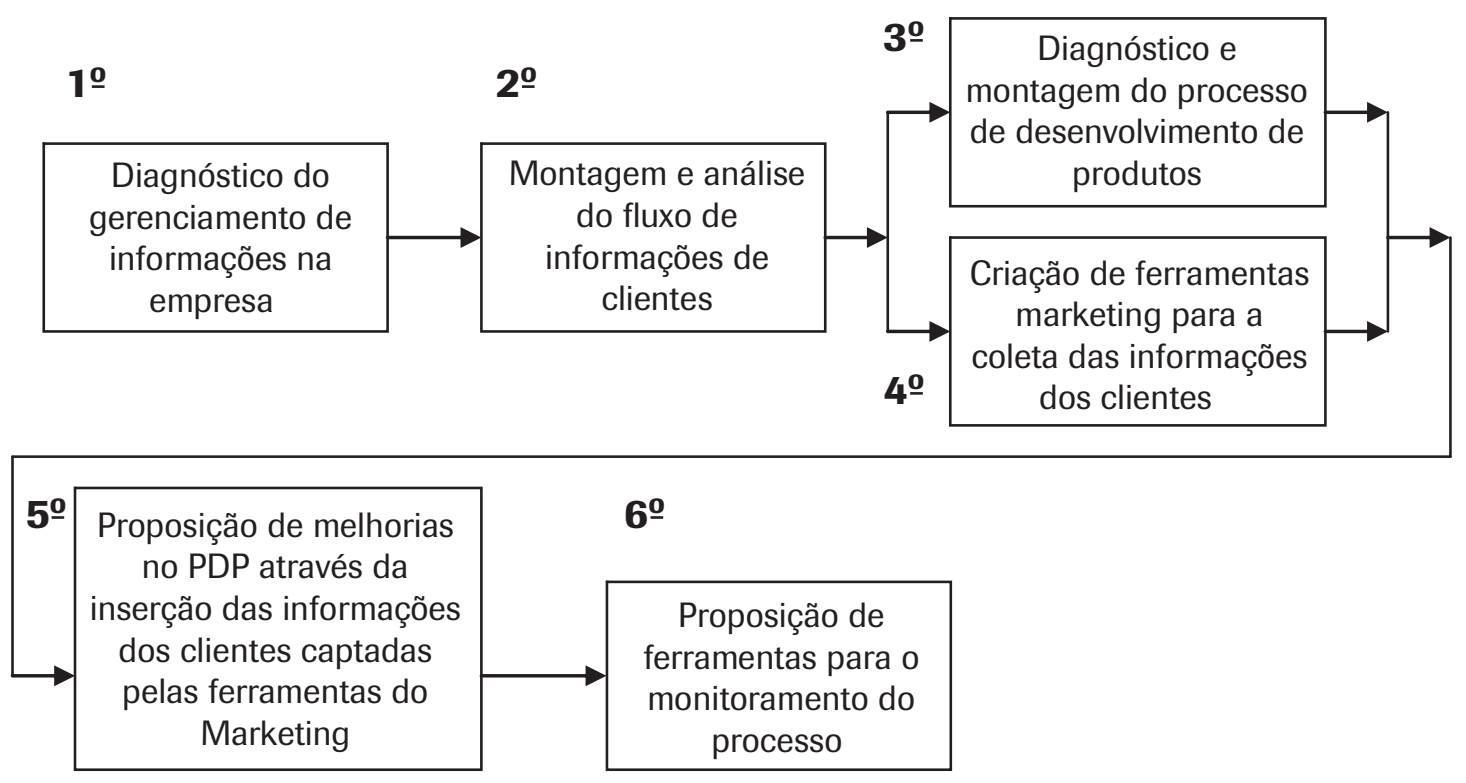

Figura 3: Delineamento da pesquisa. 
informações convergissem para a caracterização de um determinado tipo de imóvel.

Para isso, buscou-se formalizar como cada ferramenta implementada teria de entrar no processo e como cada interveniente daria sua contribuição referente às informações que os clientes ofereciam.

A importância do monitoramento do processo é incontestável, pois através desse acompanhamento foram identificados problemas e dificuldades do processo de desenvolvimento de produtos montado.

\section{O ESTUDO DE CASO}

A empresa pesquisada atua no mercado de Fortaleza há 26 anos e caracteriza-se por trabalhar no setor residencial, especificamente na incorporação de empreendimentos para a classe média e média alta.

Uma característica interessante da empresa estudada é a utilização constante de pesquisas para verificação da demanda do mercado, ferramenta que possibilita o dimensionamento e o reconhecimento das necessidades dos clientes para os quais o novo empreendimento se destina.

\subsection{Resultados da pesquisa}

Os resultados do estudo são apresentados de acordo com as etapas da metodologia aplicada. O objetivo é analisar a evolução do estudo de modo que se possa fazer entender os resultados obtidos.

Etapa 1: Diagnóstico do gerenciamento de informações na empresa.

Após uma análise das entrevistas realizadas, identificaram-se as atividades desempenhadas pelos setores da empresa que possuem contato com as informações dos clientes:

- Setor de Obras: responsável pelo atendimento do cliente durante a obra, bem como por receber informações importantes desse cliente, como sugestões de atendimento, reclamações e modificações de projeto. Também é responsável pela avaliação da satisfação do cliente durante a obra.

- Setor Comercial: responsável pelas vendas de imóveis da empresa. Uma particularidade desta empresa é que ela conta com uma loja para venda dos imóveis em um grande shopping de Fortaleza, o que gera um alto número de visitantes interessados nos imóveis.

- Setor de Contas a Receber: tem a finalidade de receber o pagamento da mensalidade de alguns clientes que pre- ferem pagar direto na loja da empresa, além de exercer a função de cobrança dos recebimentos vencidos e da renegociação de dívidas vencidas. Sendo assim, observase um potencial ponto de contato com o cliente que vem efetuar seu pagamento.

- Setor de Marketing: responsável pelo marketing da empresa. Entretanto, está mais focado na área de comunicação, ficando as demais funções do marketing (planejamento de marketing, definição do preço, promoção, produto e pesquisas) sob responsabilidade do diretor da empresa, do setor comercial e do setor de pré-incorporação. Este setor também é responsável pelo fluxo de informações de clientes provenientes do site da empresa.

- Setor de pré-incorporação: responsável pelo desenvolvimento de novos produtos na empresa, ficando sob sua responsabilidade as atividades que se iniciam na concepção do produto até o lançamento para o mercado.

- Setor de Atendimento ao Cliente (SAC): criado durante a execução da pesquisa. Responsável, inicialmente, pela entrega do imóvel ao cliente, ou seja, pelo atendimento a clientes na fase final da obra. Também é o responsável pelo atendimento ao cliente após a entrega do imóvel, durante a fase de assistência técnica e manutenção dos empreendimentos.

\section{s produtos residenciais da construção civil podem ser mais bem desenvolvidos através das informações provenientes dos clientes}

Etapa 2: Montagem e análise do fluxo de informações de clientes

Verificou-se a dificuldade de comunicação entre os setores da empresa responsáveis pela captação das informações dos clientes e o setor de desenvolvimento de novos produtos (setor de pré-incorporação), de modo que as informações deixadas pelos clientes nestes setores não eram formalmente encaminhadas ao setor de préincorporação.

Em resumo, as informações eram apresentadas espontaneamente pelos clientes através do contato que faziam com a empresa, mas os setores não tinham a preocupação de registrá-las formalmente e, muito menos, de enviá-las ao setor diretamente responsável pelo desenvolvimento de produtos.

Isso foi verificado após a montagem do DFD das informações deixadas pelos clientes em cada setor. Sendo assim, além da constatação através da entrevista realizada, o pró- 
prio setor constatava o não encaminhamento da informação quando se discutia o DFD do seu setor para com o restante da empresa. A seguir é apresentado o DFD do setor Comercial como forma de exemplificar a situação encontrada na empresa (Figura 4).

Notar, na Figura 4, que o último passo do fluxo é o cadastramento dos dados para futuros contatos e a resposta aos questionamentos. Ou seja, a informação obtida através do contato com o cliente não foi repassada para o setor de desenvolvimento de novos produtos.

Verificou-se que a informação não fluía formalmente para os setores responsáveis, ficando perdida dentro da estrutura da empresa. Isto foi detectado em todos os setores que possuem contato direto com o cliente

Etapa 3: Diagnóstico e montagem do processo de desenvolvimento de produtos (PDP)

Nenhum processo formalizado em relação ao PDP foi identificado na empresa. O que existiam eram sequências de eventos que foram sempre respeitadas no desenvolvimento de um novo produto, as quais eram frutos do conhecimento adquirido pelo setor de pré-incorporação na realização de cada novo empreendimento.

Sendo assim, formalizou-se o processo original de desenvolvimento de produto da empresa, pois sabia-se que este processo somente poderia ser melhorado a partir da visualização correta de suas etapas, atividades, participantes e gargalos.

Para formalizar o PDP de cada etapa, utilizou-se a plani- lha insumo-processo-produto (TZORTZOPOULOS, 1999), na qual cada atividade foi detalhada, informando-se que ações ou relatórios deveriam ser feitos antes de se iniciar cada processo e qual o resultado esperado ao final de cada processo (Figura 5).

No processo diagnosticado foram identificadas algumas deficiências, que foram analisadas e corrigidas na elaboração do novo processo de desenvolvimento de produto (Figura 6), no qual também foram inseridas as informações provenientes dos clientes. Na Figura 7, é exemplificada a melhoria ocorrida na etapa de concepção do produto, após a incorporação das ferramentas criadas.

Na Figura 6, perecebe-se que o PDP implantado possui dez etapas que acompanham o produto desde sua concepção até o acompanhamento do seu uso. São elas: (1) concepção do produto; (2) localização e escolha do terreno; (3) anteprojeto de arquitetura; (4) projeto legal de arquitetura; (5) projeto executivo; (6) vendas; (7) planejamento de comunicação; (8) planejamento de comercialização; (9) acompanhamento de obra; e (10) acompanhamento de uso.

Já na Figura 7, percebe-se a inserção de atividades que antes não eram realizadas, tais como: a pesquisa de concorrência, a análise das demais pesquisas e a definição e montagem das opções.

Etapa 4: Criação de ferramentas para a coleta das informações dos clientes.

As ferramentas propostas têm o objetivo de formalizar o envio das informações obtidas no contato com o cliente para

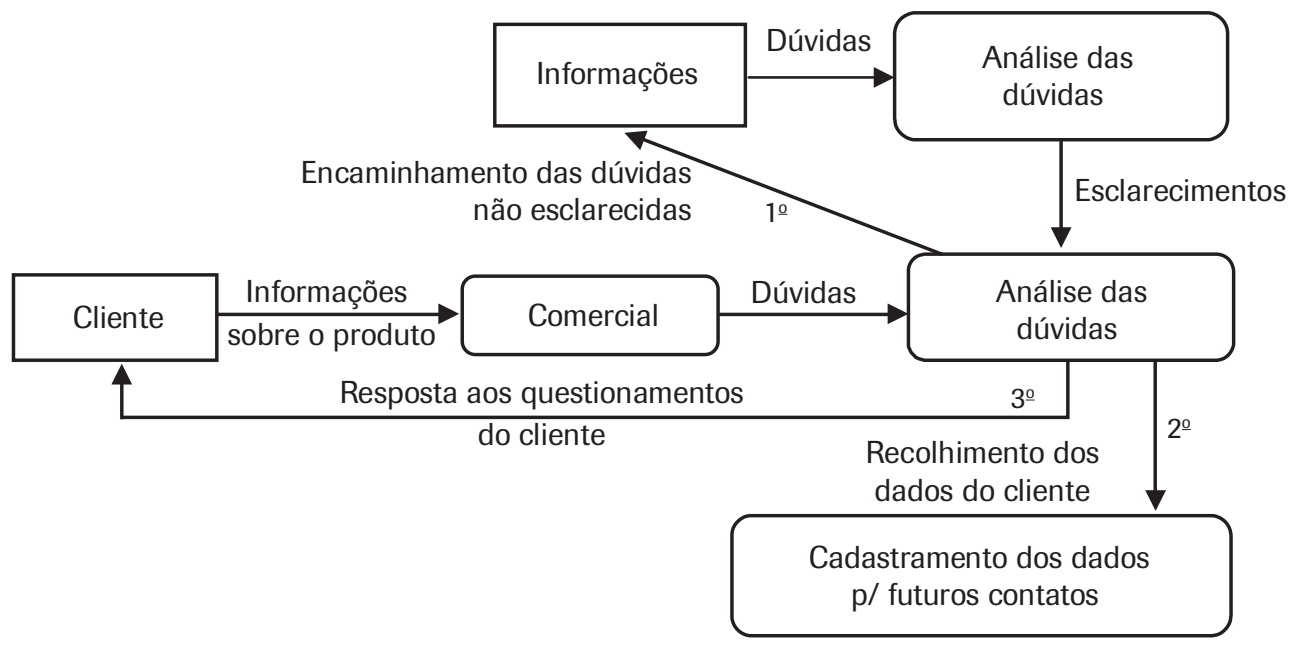

Figura 4: DFD diagnosticado no setor Comercial.

Fonte: NOBRE, 2005. 
Neto, J. P. B.; Nobre, J. A. N. 0 processo de desenvolvimento de produto imobiliário: estudo exploratório em uma incorporadora. Produção,

Insumo

Planej. estratég. da empresa;

Contato corretor

Definição de região

Potencial construtivo;

Fotografia terrenos;

Documentação

Proposta do vendedor

Estudo de implantação Arquit.

e Paisag. (c/ vagas)

Custo de construção

Def. do $\mathrm{n}^{\circ}$ de unidades

Terreno definido

Formatação da proposta
Processo

Captação de terrenos

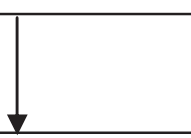

Análise e escolha dos

melhores terrenos

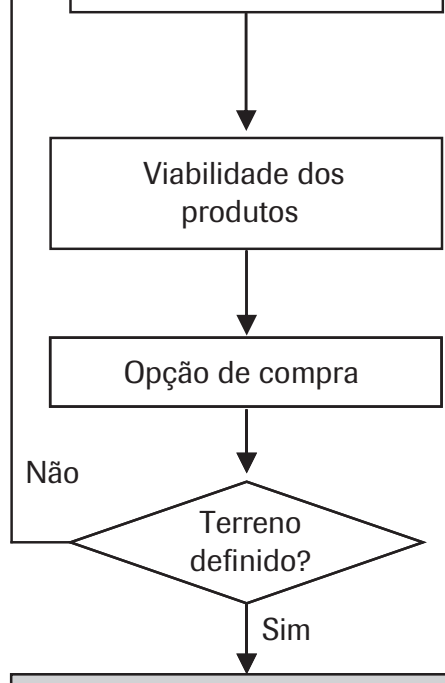

Anteprojeto de arquitetura

\section{Produto}

Estoque de terrenos; Potencial construtivo; Fotografia terrenos;

Documentação (matrícula atualiz.);

Proposta (preço e forma de pag.)

Escolha das 3 melhores opções.

Planilha de viabilidade

Definição dos terrenos viáveis

Apresentação ao Fórum

Aceitação da opção de compra Assinatura de procuração para a Prefeitura

Figura 5: Planilha de Insumo-Processo-Produto da etapa 2 do PDP - Localização e compra do terreno.

Fonte: NOBRE, 2005.

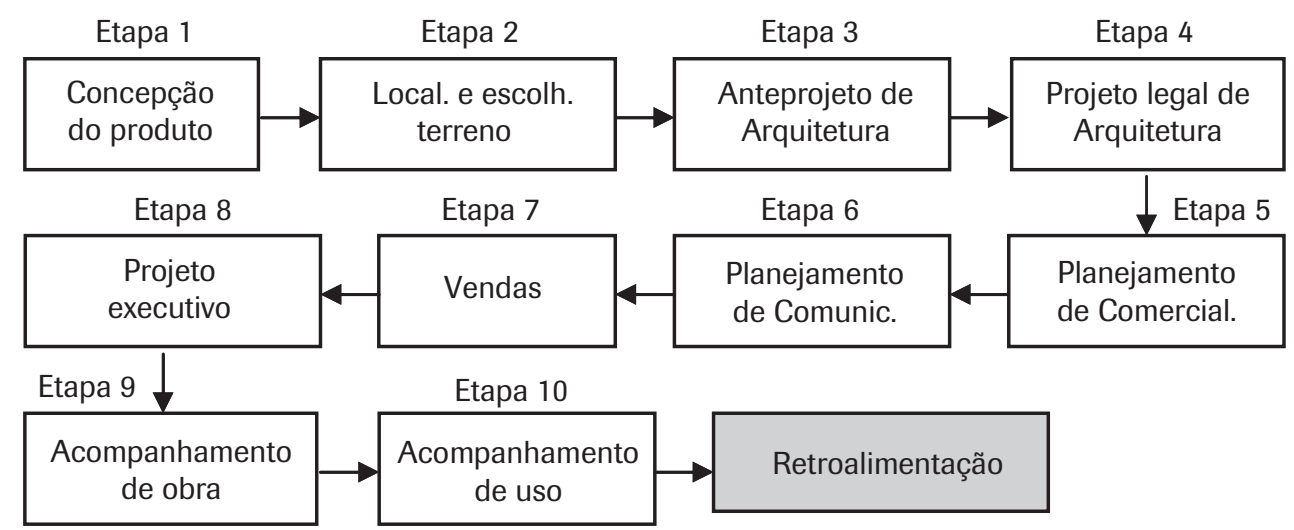

Figura 6: 0 processo de desenvolvimento de produto implantado.

Fonte: NOBRE, 2005 
o setor de pré-incorporação, de modo que estas informações sejam utilizadas no PDP.

Algumas destas ferramentas foram somente propostas e outras foram sugeridas e testadas, conforme detalhado a seguir:

- Ferramenta 1: Pesquisa com clientes potenciais interessados

Para o setor Comercial, foi criado um questionário para pesquisa com as pessoas que passavam pela loja interessadas em comprar um apartamento. Estas pessoas foram

\section{Processo Diagnosticado}

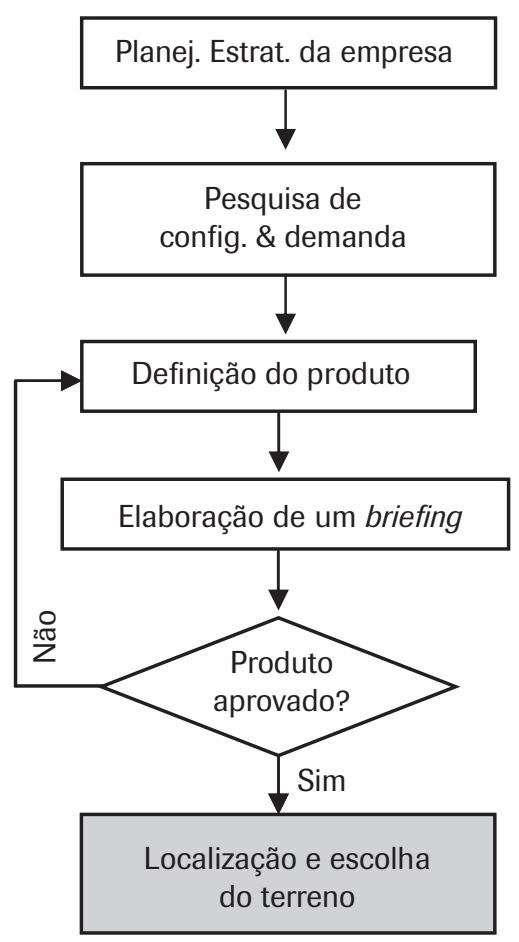

caracterizadas como clientes potenciais; ou seja, poderiam se tornar clientes se a empresa soubesse atender às suas necessidades por um imóvel. Sendo assim, esta foi uma ferramenta testada.

- Ferramenta 2: Pesquisa on-line com prospects

Para o outro canal de contato, a página eletrônica (site) da empresa, também foi criada uma ferramenta para coleta de dados dos visitantes interessados em adquirir apartamentos. Trata-se de uma pequena pesquisa com dez

\section{Processo Implantado}

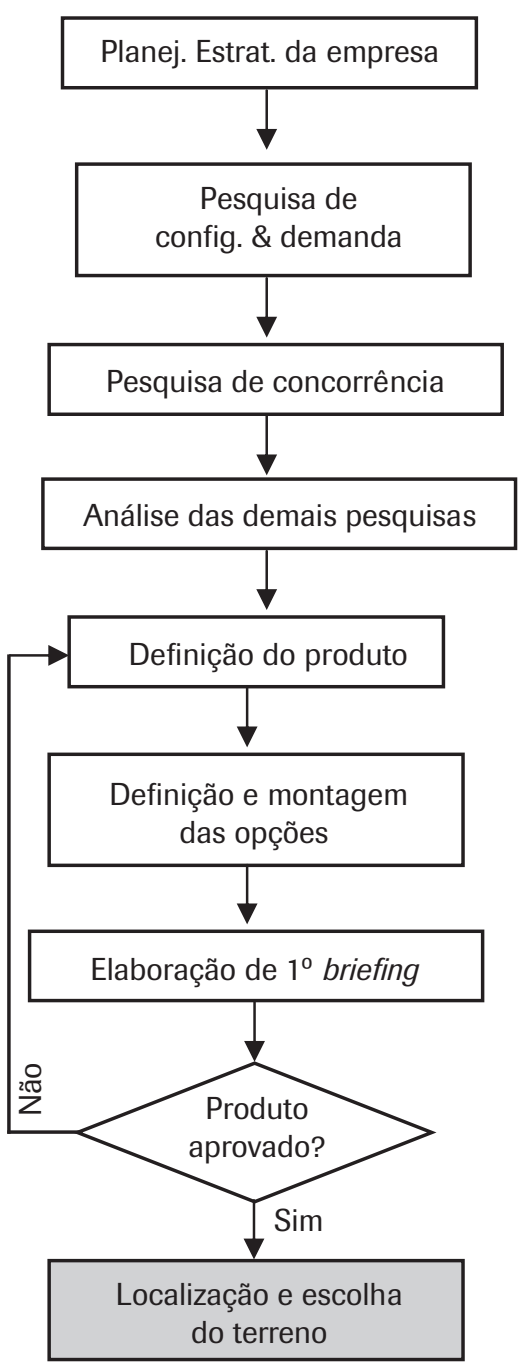

Figura 7: Comparativo entre as etapas de concepção do produto do processo diagnosticado e do processo implantado. 
perguntas que o cliente deve preencher, caso não encontre algum imóvel que lhe interesse na referida página. Como se percebe esta ferramenta também foi testada.

- Ferramenta 3: Pesquisa com os clientes que visitam as obras

Para os clientes que visitam as obras da empresa, criou-se um questionário no qual se passou a recolher informações sobre frequência de visitas do cliente à obra, motivo da visita, avaliação do padrão de acabamento do imóvel, das áreas dos ambientes, avaliação da satisfação do cliente em relação ao seu apartamento, da satisfação com a empresa etc. O objetivo é ampliar a captação das informações dos clientes em relação à obra. Este roteiro de perguntas foi elaborado junto com os responsáveis pelo atendimento, pois se buscou formalizar o que já era perguntado, de modo que os questionamentos não ficassem fora do contexto da visita do cliente. Também foi uma ferramenta testada.

- Ferramenta 4: Pesquisa com os clientes que frequentam o setor de contas a receber

Para o setor de contas a receber, deve-se obedecer ao mesmo raciocínio da ferramenta aplicada na obra: aproveitar o contato do cliente para captar informações que sejam interessantes para o setor de pré-incorporação. Esse questionário utiliza o mesmo modelo aplicado na obra. Neste caso, a ferramenta foi apenas proposta, não tendo sido testada.

- Ferramenta 5: Pesquisa do portal do cliente

O portal do cliente, ainda não criado, será uma área específica dentro da página eletrônica da empresa. O cliente (que já possui um imóvel da empresa) poderá verificar seu saldo devedor, o andamento da sua obra, emitir boletos de pagamentos, sendo este acesso delimitado por senhas; ou seja, será uma área destinada somente a clientes da empresa. Também é uma ferramenta que só foi proposta.

- Ferramenta 6: Pesquisa de satisfação na entrega dos imóveis

O setor de atendimento a clientes ficou responsável pela realização de uma pesquisa no momento da entrega das unidades do empreendimento que estavam sendo concluídas. Essa pesquisa tem o objetivo de verificar a satisfação do cliente no momento do recebimento da sua unidade, que é um momento único no processo, pois é onde se verifica a primeira reação do cliente ao seu imóvel pronto. Esta foi uma ferramenta testada.
- Ferramenta 7: Matriz satisfação-importância

$\mathrm{Na}$ fase de acompanhamento de uso (após a conclusão da obra), propôs-se a montagem da matriz satisfaçãoimportância (MOURÃO et al., 2004), a partir dos resultados da pesquisa de satisfação que deve ser realizada após a conclusão da obra, no prazo determinado de 2 e de 5 anos após a conclusão da obra. Esta ferramenta não foi testada, somente proposta.

Todas estas ferramentas tiveram seus relatórios de resultados formalmente inseridos em etapas do processo, existindo, também, uma atividade de análise das pesquisas realizada na empresa.

Etapa 5: Proposição de melhorias no PDP através da inserção das informações dos clientes captadas pelas ferramentas.

O PDP diagnosticado foi melhorado por meio da inserção das informações dos clientes captadas pelas ferramentas desenvolvidas neste estudo. As ferramentas criadas foram inseridas no DFD de cada setor para se verificar o novo fluxo de informações e se a informação estaria chegando ao setor responsável pelo desenvolvimento de novos produtos. Isto foi verificado em todos os setores onde se aplicaram as ferramentas. Para mostrar este resultado, segue abaixo o DFD geral da empresa antes (Figura 8) e depois da aplicação das ferramentas de pesquisa (Figura 9).

Além disso, também se alterou a ordem de algumas atividades (ex.: opção de compra, efetivação da compra do terreno, etc.) com o objetivo de tornar o processo mais consistente.

Sendo assim, além da alteração do processo quanto à inserção das ferramentas desenvolvidas, também se discutiu a melhoria do processo como um todo, pois algumas atividades estavam mal posicionadas, ocasionando possíveis custos desnecessários, como por exemplo as atividades de consulta prévia e efetivação da compra do terreno.

Vale salientar que o número de etapas, bem como a denominação destas, não se alterou da passagem do PDP diagnosticado para o PDP proposto. Somente se alteraram as atividades dentro das etapas, conforme mostra o Quadro 2 (em negrito estão as atividades que foram alteradas ou inseridas no processo).

Etapa 6: Proposição de ferramentas para o monitoramento do processo

A empresa decidiu-se por utilizar a velocidade de vendas como "termômetro" para o desenvolvimento de produtos. Portanto, levantou-se o histórico dessa velocidade para se estabelecer um parâmetro de evolução da melhoria do processo. Se a velocidade de vendas de um determinado 
Neto, J. P. B.; Nobre, J. A. N. 0 processo de desenvolvimento de produto imobiliário: estudo exploratório em uma incorporadora. Produção, v. 19 , n. 1 , p. $087-104,2009$

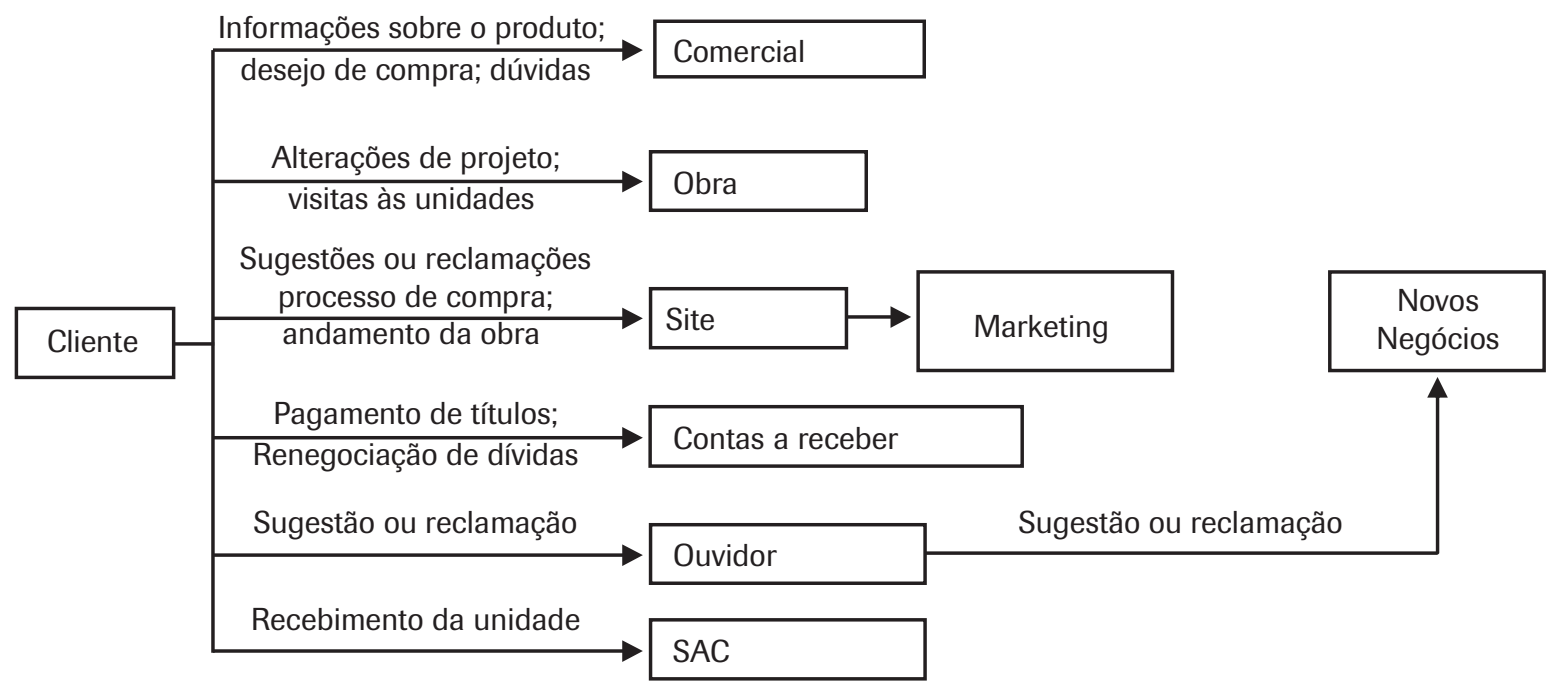

Figura 8: DFD geral da empresa antes da implantação das ferramentas de captação das informações dos clientes.

Fonte: Nobre, 2005

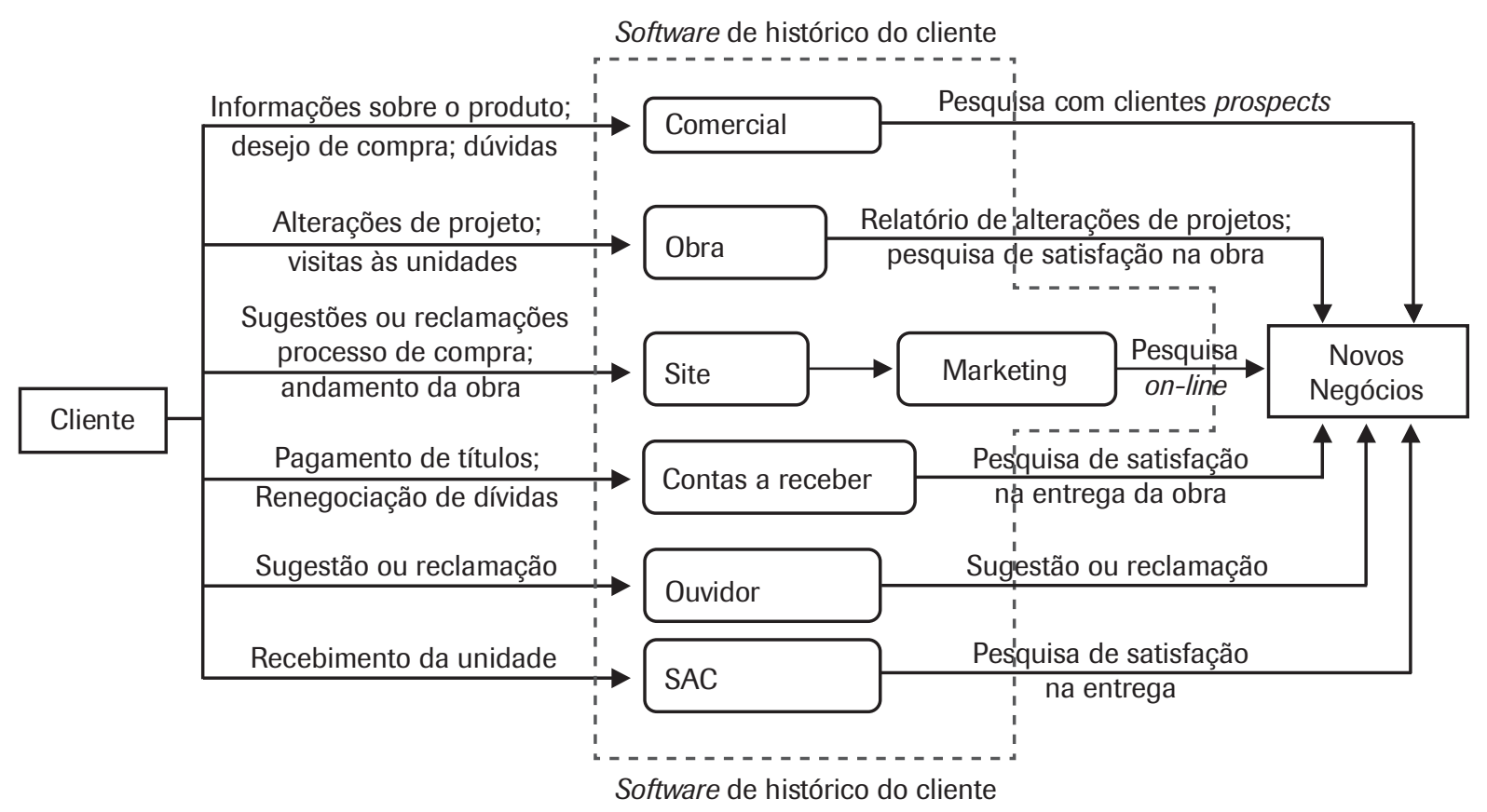

Figura 9: DFD geral da empresa após a implantação das ferramentas de captação das informações dos clientes. 
Neto, J. P. B.; Nobre, J. A. N. 0 processo de desenvolvimento de produto imobiliário: estudo exploratório em uma incorporadora. Produção, v. 19, n. 1 , p. $087-104,2009$

Quadro 2: Comparativo entre o processo diagnosticado e o processo proposto.

\begin{tabular}{lc}
\hline \multicolumn{1}{c}{ DIAGNÓSTICO } & \multicolumn{1}{c}{ PROPOSTO } \\
\hline & ETAPA 1 \\
\hline Planejamento estratégico da empresa; & Planejamento estratégico da empresa; \\
$\begin{array}{l}\text { Pesquisa de configuração \& demanda (não utilizada } \\
\text { formalmente); }\end{array}$ & $\begin{array}{l}\text { Pesquisa de configuração \& demanda (utilizada formalmente); } \\
\text { Análise dos produtos desenvolvidos; }\end{array}$ \\
$\begin{array}{ll}\text { Definição do produto; } \\
\text { Elaboração de um briefing (não realizada formalmente); }\end{array}$ & Definição do produto; \\
& Definição e montagem das opções; \\
& Elaboração do 1o briefing (realizado formalmente) \\
\hline Captação de terrenos; & ETAPA 2 \\
Análise e escolha dos melhores terrenos; & Captação de terrenos; \\
Viabilidades dos produtos; & Análise e escolha dos melhores terrenos; \\
& Viabilidade dos produtos; \\
& Opção de compra. \\
\hline
\end{tabular}

ETAPA 3

Anteprojeto de arquitetura e paisagismo;

Opção de compra;

Orçamento preliminar;

\section{Elaboração do 2o briefing;}

Anteprojeto de arquitetura e paisagismo;

Consulta prévia na Prefeitura;

Orçamento preliminar;

Efetivação da compra do terreno.

\begin{tabular}{ll}
\hline & ETAPA 4 \\
\hline - Execução do projeto legal de arquitetura; & - Parcelamento do solo; \\
- Efetivação da compra do terreno; & - Execução do projeto legal de arquitetura; \\
- Aprovação do projeto legal na Prefeitura; & - Aprovação do projeto legal de arquitetura; \\
- Execução dos demais projetos para aprovação; & - Execução dos demais projetos para aprovação; \\
- Retirada de alvará de construção; & - Retirada de alvará de construção; \\
- Retirada de registro de incorporação. & - Retirada de registro de incorporação. \\
\hline
\end{tabular}

- Execução do mapa preço-valor;

- Definição do preço/tabelas de vendas;

- Avaliação financeira da tabela de vendas;

- Definição das estratégias de comercialização;

- Avaliação financeira das estratégias de comercialização.

ETAPA 5

- Execução de mapa preço-valor;

- Definição de formas de financiamento;

- Definição do preço/tabela de vendas;

- Avaliação financeira das tabela de vendas;

- Definição dos preços das opções;

- Definição das estratégias de comercialização;

- Avaliação financeira das estratégias de comercialização.

ETAPA 6

- Execução de maquete, filme e plantas humanizadas

- Planejamento de comunicação de lançamento;

- Planejamento de ponto de venda;

- Criação/execução da comunicação;

- Execução do ponto de venda;

- Veiculação e execução da campanha.

- Execução de maquete, filme e plantas humanizadas

- Planejamento de comunicação de lançamento;

- Planejamento de ponto de venda;

- Criação/execução da comunicação;

- Planejamento de sustentação;

- Planejamento de relacionamento;

- Execução do ponto de venda;

- Veiculação e execução da campanha.

ETAPA 7

- Definição dos preços das opções;

- Elaborar contrato de compra e venda;

- Cadastramento do empreendimento no sistema;

- Execução das estratégias de comercialização;

- Execução da comunicação de relacionamento.
- Elaboração do contrato de compra e venda;

- Cadastramento do empreendimento no sistema;

- Execução das estratégias de comerc.;

- 1 análise do produto;

- Análise e reestruturação das vendas;

- Execução da comunicação de relacionamento. 
Neto, J. P. B.; Nobre, J. A. N. 0 processo de desenvolvimento de produto imobiliário: estudo exploratório em uma incorporadora. Produção, v. 19, n. 1, p. $087-104,2009$

ETAPA 8

Não se realizou nenhuma alteração a partir do PDP diagnosticado, devido a sua consistência em relação a esta etapa.

ETAPA 9

- Controle de alteração de projetos;

- Verificação do memorial descritivo;

- Procedimento de entrega da unidade.
- Controle de alteração de projetos

- Captação de informação dos clientes durante a obra;

- Verificação do memorial descritivo;

- Procedimento de entrega da unidade;

- Verificação da satisfação na entrega da obra;

- 2a Análise do produto.

ETAPA 10

- Análise das solicitações dos clientes;

- Atendimento das solicitações;

- Medição pós-obra da satisfação dos clientes.
- Análise das solicitações dos clientes;

- Atendimento das solicitações;

- 1a Medição pós-obra da satisfação dos clientes;

- Execução da 1a Matriz de satisfação-importância;

- 2a Medição pós-obra da satisfação dos clientes;

- Execução da 2a Matriz satisfação-importância;

- 3a Análise do produto.

Fonte: Nobre, 2005

produto tivesse sua evolução inferior ao histórico da empresa, o processo de desenvolvimento do produto em questão deveria ser reavaliado.

Além disso, deve-se verificar novamente o grau de saturação do mercado, para que se analise se o erro está no produto ou na saturação do mercado, o que também se caracterizará como um erro do PDP, pois a ocorrência dessa saturação deveria estar prevista no processo.

Foi desenvolvido um cronograma que também pode ser utilizado para o monitoramento do processo. Dessa forma, consegue-se medir o tempo real de cada atividade em um determinado produto. Após a comparação entre os cronogramas dos outros produtos, foram identificados problemas ou dificuldades no processo que deveriam ser estudados para serem melhorados.

\subsection{Conclusão do estudo de caso}

Algumas melhorias no novo projeto já foram observadas frente aos resultados das ferramentas aplicadas, ou seja, algumas informações provenientes dos clientes e prospects já foram realimentadas no processo do novo empreendimento, entre elas: a inserção de quadra poliesportiva, a elevação da guarita de segurança da entrada dos empreendimentos, e a melhoria na apresentação das plantas humanizadas no fôlder do empreendimento.

Alguns outros itens foram observados, mas a empresa não acatou as informações apresentadas devido a diversos fatores, sendo o mais preponderante o aumento do custo da obra para a realização das alterações. Dentre eles, podese considerar: revestimento completo (piso e parede até a altura do teto) na cozinha e banheiros dos apartamentos; não mais utilização do revestimento do piso de um produto anterior para os próximos empreendimentos destinados ao mesmo público; e eliminação dos apartamentos existentes no pavimento térreo.

Apesar de a pesquisa ser realizada em uma única empresa, pode-se considerar a sua importância devido à existência de diferentes pontos de estudo. E sendo o objetivo da pesquisa a melhoria do PDP como um todo, somente seria possível através do estudo aprofundado em uma única empresa, abordando-se as diversas etapas.

\section{CONSIDERAÇõES FINAIS}

O estudo analisou o processo completo dentro de uma única empresa, mostrando a continuidade do fluxo de informações nas diversas fases de interação com o cliente. Para isso foi fundamental que a empresa tivesse produtos nas diversas fases do PDP, pois se analisou o processo completo em um espaço de tempo reduzido.

Um limitador do projeto foi o não contato formalizado com os projetistas, já que eles estavam localizados em outros estados do País. Este trabalho poderia evoluir mais ainda a partir da conexão das informações provenientes da empresa em análise com as informações provenientes dos projetistas terceirizados.

As características do produto lançado durante a pesquisa já foram baseadas nos resultados do estudo. Todos os itens que o compõem (configuração, localização, acabamento, for- 
ma de pagamento) foram baseados em valores dos clientes que foram expostos pela melhoria do processo de desenvolvimento de produto.

Assim, o gerenciamento de informações sobre o PDP possibilitou o desenvolvimento das ferramentas necessárias para a melhoria desse processo na empresa. Esta visão foi a âncora para a obtenção das informações provenientes dos clientes.

Este artigo considerou que a melhoria do PDP é a inserção da voz do cliente nesse processo. Sendo assim, o objetivo desta pesquisa foi atingido, pois, através das diversas ferramentas desenvolvidas, da análise e melhoria dos DFD's e do fluxo do processo, conseguiu-se inserir as informações provenientes dos clientes no processo e melhorá-lo através disso. O DFD apresenta claramente o fluxo de informação (emissor, receptor e mensagem) que ocorre no processo de desenvolvimento do produto de uma incorporadora, porém não mostra o detalhamento apresentado por Pati e Augenbroe (2007) e Zhu e Augenbroe (2007), necessário ao desenvolvimento de um API, bem como um detalhamento hierárquico da informação.

As informações passaram a chegar ao setor responsável pelo desenvolvimento de novos produtos, fato verificado através do DFD montado após a implantação das ferramentas de captação das informações dos clientes.

A contribuição deste trabalho está em demonstrar como os produtos residenciais da construção civil podem ser mais bem desenvolvidos através das informações provenientes dos clientes, de modo que o produto final possua o máximo de valor agregado e o mínimo de rejeição por parte do mercado.

Ademais, contribui no aprimoramento do conceito de PDP para o setor da construção civil, pois se discutiu a extrapolação do conceito de processo de projeto para o novo conceito de PDP que foi adotado neste trabalho.

Pretende-se dar continuidade a este estudo a partir do acompanhamento e monitoramento das ferramentas implantadas, avaliando suas facilidades e dificuldades, bem como trazendo melhorias que possam agilizar o processo e aprimorar as informações obtidas dos clientes.

Para trabalhos futuros, sugere-se a análise separada de cada etapa do processo em diversas empresas, verificando a resposta de cada uma delas para as ferramentas implantadas na etapa específica do processo.

\section{Artigo recebido em 12/07/2006 Aprovado para publicação em 10/10/2008}

\section{REFERÊNCIAS}

AMARAL, D. C. Arquitetura para gerenciamento de conhecimentos explícitos sobre o processo de desenvolvimento de produto. 2002. Tese (Doutorado em Engenharia Mecânica) - Escola de Engenharia de São Carlos, Universidade de São Paulo, São Carlos, 2002.

BARROS NETO, J. P. Proposta de um modelo de formulação de estratégias de produção para pequenas empresas de construção habitacional. 1999. Tese (Doutorado em Administração) Programa de Pós-Graduação em Administração, Universidade Federal do Rio Grande do Sul, Porto Alegre, 1999.

BENEDICTIS, C. C.; AMARAL, D. C.; ROZENFELD, H. Evaluation of the existing methods and tools for product development process modeling. Product: management \& development, Florianópolis, v. 2, n. 2, p. 19-27, mar., 2004.
BERNARDES, M. M. S. Método de análise do processo de planejamento da produção de empresas construtoras através do estudo de seu fluxo de informação: proposta baseada em estudo de caso. 1996. Dissertação (Mestrado em Engenharia Civil) - Programa de Pós-Graduação em Engenharia Civil, Universidade Federal do Rio Grande do Sul, Porto Alegre, 1996.

CINTRA, M. A. H.; AMORIM, S. R. L. Sistemas de informação no gerenciamento de projetos aplicação do DFD: diagrama de fluxo de dados. In: III Congresso de Engenharia Civil, Juiz de Fora, 1998.

COELHO, E. Sistema de informações para o auxílio no desenvolvimento de novos produtos. 1998. Dissertação (Mestrado em Engenharia de Produção) - Programa de Pós-Graduação em Engenharia de Produção, Universidade Federal de Santa Catarina, Florianópolis, 1998.
COOPER, D.R., SCHINDLER, P.S. Métodos de pesquisa em administração. Porto Alegre: Bookman, 2003.

DELPHI GROUP. BPM. Market milestone report, 2003 Disponível em: <http://www. .scribd. com>. Acesso em: 01 mar. 2008.

FABRÍCIO, M. M. Projeto Simultâneo na Construção de Edifícios. 2002. Tese (Doutorado em Engenharia Civil) - Programa de PósGraduação em Engenharia de Construção Civil e Urbana, Escola Politécnica da Universidade de São Paulo, São Paulo, 2002.

FISHER, L. (ed.). The Workflow Handbook. WfMC, 2004

GIROTO, L. F. O Planejamento do Produto e a Gestão da Percepção Valorgráfica do 
Consumidor. 1998. Dissertação (Mestrado em Engenharia Civil) - Programa de PósGraduação em Engenharia de Produção, Universidade Federal de Santa Catarina, Florianópolis, 1998.

KELLY, J. Making client values explicit in value management workshops. Construction Management and Economics, 25, p. 435-442, 2007.

MIRON, L. I. G. Proposta de Diretrizes para o Gerenciamento dos Requisitos do Cliente em Empreendimentos da Construção. 2002. Dissertação (Mestrado em Engenharia Civil) Programa de Pós-Graduação em Engenharia Civil, Universidade Federal do Rio Grande do Sul, Porto Alegre, 2002.

MIRON, L. I. G.; FORMOSO, C. T. Gerenciamento dos requisitos do cliente em empreendimentos habitacionais. In: IX Encontro Nacional de Tecnologia do Ambiente Construído, Foz do Iguaçu: 2002.

MOURÃO, Y. R.; BARROS NETO, J. P.; SANTOS, A. P. S. A pesquisa de satisfação como forma de verificar a discordância entre os requisitos dos clientes e as especificações dos projetistas. In: X Encontro Nacional de Tecnologia do Ambiente Construído, São Paulo, 2004.

NOBRE, J. A. P. Proposição de Melhorias no Processo de Desenvolvimento de Produto da Construção Civil Mediante a Captação das Informações dos Clientes. 2005. Dissertação
(Mestrado em Administração) - Curso de Mestrado Profissional em Administração, Universidade Federal do Ceará, 2005.

OLIVEIRA, M. C. G. Os fatores determinantes da satisfação pós-ocupacional de usuários de ambientes residenciais. 1997. Dissertação (Mestrado em Engenharia de Produção) Programa de Pós-graduação em Engenharia de Produção, Universidade Federal de Santa Catarina, Florianópolis, 1997.

PATI, D. e AUGENBROE, G. Integrating formalized user experience within building design models. Computer-Aided Civil and Infrastructure Engineering, 22, p. 117-132, 2007.

PORTO, C.B. Redes de empresas: uma nova configuração organizacional para as micro, pequenas e médias empresas da indústria da construção civil - subsetor de edificações. 1999. Dissertação (Mestrado em Engenharia Civil) Programa de Pós-Graduação em Engenharia Civil Universidade Federal Fluminense, Niterói, 1999.

SCHEER, A. W. Business Process Engineering: reference models for industrial enterprises, Heidelberg, Springer-Verlag, 1998.

SILVA, C. E. S. Método para Avaliação do Desempenho do Processo de Desenvolvimento de Produtos. 2001. Tese (Doutorado em Engenharia de Produção) - Programa de Pós-Graduação em Engenharia de Produção, Universidade Federal de Santa Catarina, Florianópolis, 2001.
TZORTZOPOULOS, P. Contribuições para o desenvolvimento de um modelo do processo de projeto de edificações em empresas construtoras incorporadoras de pequeno porte. 1999. Dissertação (Mestrado em Engenharia Civil) - Programa de Pós-Graduação em Engenharia Civil, Universidade Federal do Rio Grande do Sul, Porto Alegre, 1999.

YIN, R.K. Estudo de Caso: Planejamento e Método. Porto Alegre: Bookman, 2001.

YOURDON, E. Análise Estruturada Moderna. Rio de Janeiro: Campus, 1990.

ZEGARRA, S. L. V. Diretrizes para a elaboração de um modelo de gestão dos fluxos de informações como suporte à logística em empresas construtoras de edifícios. 2000. Dissertação (Mestrado em Engenharia Civil) - Programa de Pós-Graduação em Engenharia de Construção Civil, Escola Politécnica da Universidade de São Paulo, São Paulo, 2000

ZENONE, L.C. Costumer Relationship Management (CRM): conceitos e estratégias - mudando a estratégia sem comprometer o negócio. São Paulo: Atlas, 2001.

ZHU, Y.; AUGENBROE, G. A conceptual model for supporting the integration of interorganizational information processes of AEC projects. Automatiom in Construction, 15, p. 200-211, 2006

\section{SOBRE OS AUTORES}

\section{José de Paula Barros Neto}

Universidade Federal do Ceará - UFC

Departamento de Engenharia Estrutural e Construção Civil.

End.: Universidade Federal do Ceará, Campus do Pici, s/n - Bloco 710 - Fortaleza - CE - 60.455-760 - Brasil

Tel: (85) 3366-9600 / Fax: (85) 3366-9601

E-mail:.jpbarros@ufc.br

\section{João Adriano Ponciano Nobre}

Construtora Marquise e Universidade Federal do Ceará

Endereço: Av. Pontes Vieira, 1838 - Dionísio Torres - Fortaleza - CE - 60.130-241 - Brasil

Tel: (85) 8826-2209

E-mail: adrianonobre@marquise.com.br 